\title{
Human Papillomavirus Negative
}

National Cancer Institute

\section{Source}

National Cancer Institute. Human Papillomavirus Negative. NCI Thesaurus. Code C131488.

Indicates that human papillomavirus has not been detected in a sample. 